\title{
A Novel Cyclic Process Involving Zinc for Separating Silver from Lead-Free Solder Residue
}

\author{
Byung-Su Kim*, Jae-chun Lee and Soo-Kyung Kim \\ Korea Institute of Geoscience \& Mineral Resources (KIGAM), 92 Gwahang-no, Yuseong-gu, Daejeon 305-350, Korea
}

In recent years, the major issue posed by the recycling of tin-lead and lead-free solder residues is to recycle effectively lead-free solder residues because large volume of lead-free solder residues has been generated from electric and electronic industry as the environmental regulation becomes to be strictly in Europe. In general, the lead-free solder residues are generated from the step to affix components to printed circuit boards, which contains $2-4 \%$ of silver and $90-93 \%$ of tin. In this study, a novel cyclic process to separate silver from the lead-free solder residues using a metal solvent has been developed. The process uses zinc as a metal solvent which selectively forms intermetallic compounds with silver, followed by the volatilization separation step to recover zinc which can be reused as the metal solvent. Based on the results obtained, up to $90 \%$ of the silver in a lead-free solder residue was calculated to be separated into the dross phase through the sixth silver separation stage using the proposed process. This paper is only concerned with the results for the separation of silver from a lead-free solder residue using zinc as a metal solvent. [doi:10.2320/matertrans.M2010128]

(Received April 12, 2010; Accepted April 19, 2010; Published June 25, 2010)

Keywords: recycling, lead-free solder residues, volatilization separation, metal solvent

\section{Introduction}

There is growing global interest in eliminating lead from electronic products due to the harmful effect of it in environmental on health issue. Therefore, a switch to leadfree solder instead of lead solder for affixing components to printed circuit boards in electric and electronic industry has been rapidly increased. Based on the recent investigation, it is estimated that around 1,000 tons of lead-free solder residues containing $2 \sim 4 \%$ of silver, $90 \sim 93 \%$ of tin, $0.4 \sim 0.5 \%$ of copper and $1.2 \sim 1.4 \%$ of lead are generated each year in Korea. ${ }^{1)}$ It is also expected that the amount of lead-free solder residues generated will increase in future with enforcing the environmental regulation strictly over the world. At the present time, few companies are known to produce tin metal from the lead-free solder residues by using the electrolytic refining process which is used to produce tin metal from tin ores. $^{1,2)}$ However, the process for recyclers recycling solder residues has drawbacks like high cost investment and waste water generation.

Therefore, it would be highly desirable to find an alternative process for recycling lead-free solder residues. The present research is concerned with experimental investigations for separating silver from the lead-free solder residues using zinc as a metal solvent, and recovering tin and zinc through the volatilization separation step. Figure 1 shows the flow sheet of this suggested process. The suggested process consisted of two major steps, silver separation and zinc volatilization separation steps. It is thus thought that the suggested process is relatively simple and low cost investment compared with the electro refining process. In this paper, the separation of silver from a lead-free solder residue using zinc as a metal solvent is investigated.

\section{Choice of Metal Solvent}

The phase diagrams of silver-tin and tin-zinc systems are

${ }^{*}$ Corresponding author, E-mail: bskim@kigam.re.kr shown in Figs. 2-3.,4) The silver-tin system displays that the solubility of silver in liquid tin is relatively small in degree of about 3.5 mass $\%$ at the temperature of $494 \mathrm{~K}$, while the tinzinc system does that the solubility of zinc in liquid tin is a little large in degree of about 8.8 mass $\%$ at the temperature of $472 \mathrm{~K}$. It was also reported that the silver has a stronger affinity for zinc than for tin. ${ }^{5-7)}$ Based on the investigations, it was expected that zinc preferentially separates silver from liquid lead-free solder residues during controlling the melting temperature in order to minimize the solubility of silver in liquid tin. Therefore, zinc metal was selected as a metal solvent for preferentially separating silver from liquid leadfree solder residues which are mainly composed of tin and silver.

\section{Experimental}

Experiments were carried out in an alumina crucible $(10 \mathrm{~cm}$ height and $7 \mathrm{~cm}$ inner diameter) using a box type furnace (having $\mathrm{SiC}$ heating elements) under air atmosphere. The temperature was measured by a K-type thermocouple. A uniform temperature profile of $\pm 5 \mathrm{~K}$ was achieved over the input material. The lead-free solder residue used in this work was first melted at $673 \mathrm{~K}$ to remove organic materials like epoxy, resin and so on and high temperature oxide compounds like $\mathrm{Al}_{2} \mathrm{O}_{3}, \mathrm{CaO}, \mathrm{MgO}$ and $\mathrm{SiO}_{2}$ before doing the silver separation experiment, followed by the addition of zinc as a metal solvent. The refractory oxides could be removed by the gravity difference. The addition amount of zinc used for the experimental purpose was calculated by considering the formation of a zinc-silver alloy of $\mathrm{Ag}_{2} \mathrm{Zn}_{5}$ among several zinc-silver compounds like $\mathrm{Ag}_{2} \mathrm{Zn}, \mathrm{Ag}_{2} \mathrm{Zn}_{3}$ and $\mathrm{AgZn}_{9}$. Also, the addition amount of zinc was calculated by considering the solubility of zinc at the eutectic temperature of the tin-zinc system as shown in Fig. 3. The silver separation experiments started at $723 \mathrm{~K}$ and lasted $10 \mathrm{~min}$ with stirring (200 RPM) to alloy totally zinc with the tinsilver alloy obtained from the pretreatment, and then cooled down with stirring (200 RPM) until $472 \mathrm{~K}$ which is close to 


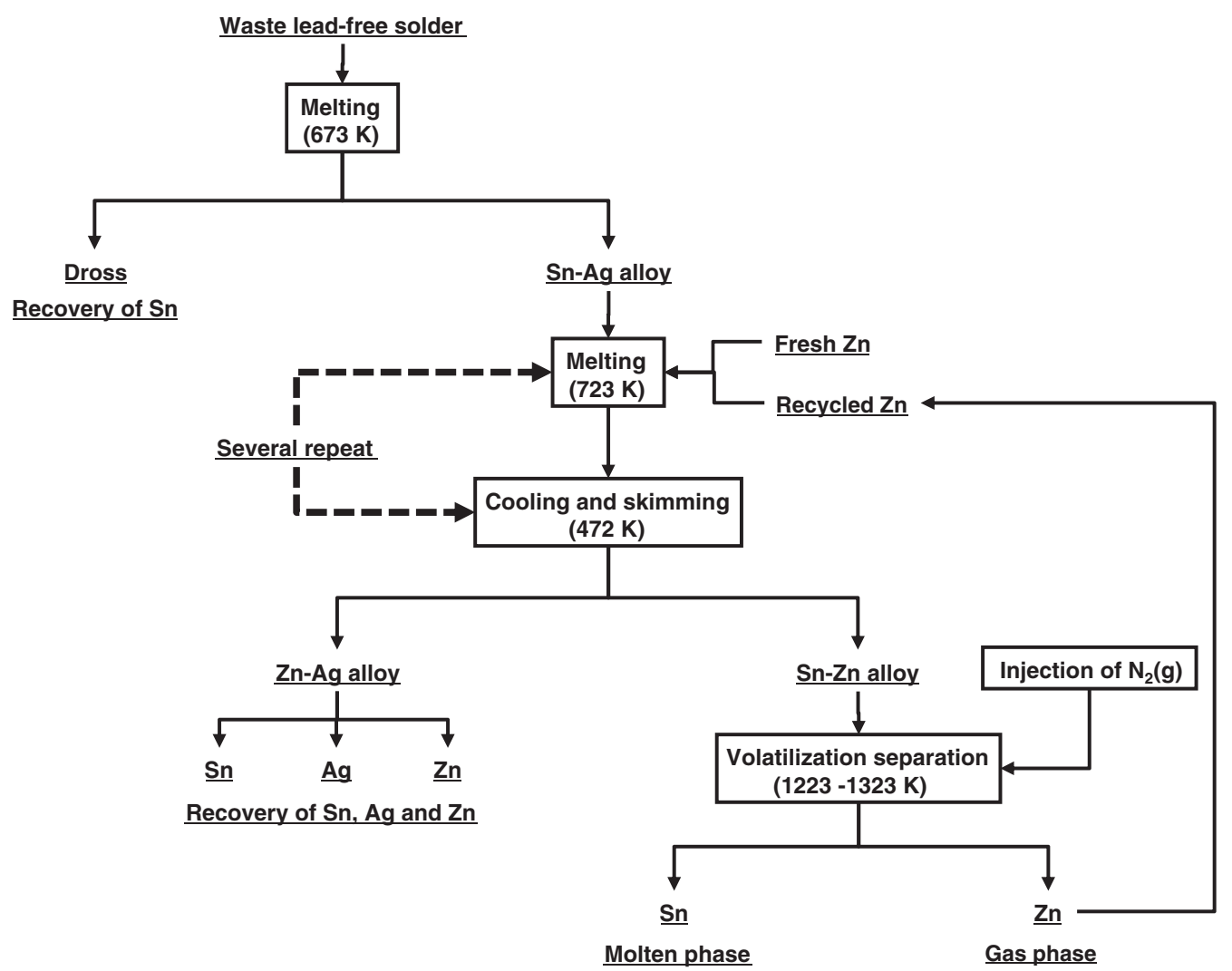

Fig. 1 Flow sheet of a novel cyclic process proposed to separate silver from lead-free solder residues.

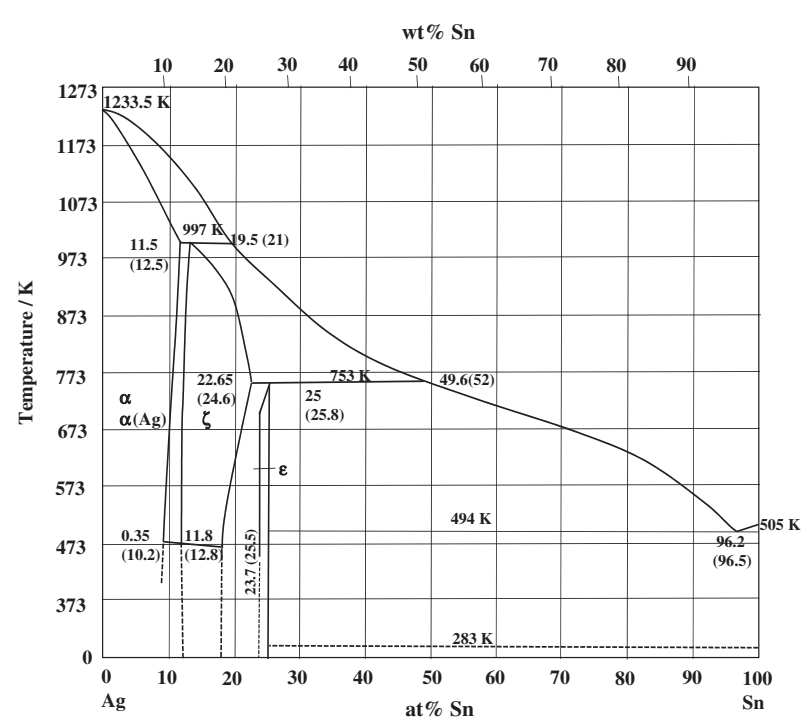

Fig. 2 Phase diagram of Ag-Sn system. ${ }^{3}$

the solubility temperature of tin-zinc alloy. During the cooling, the zinc-silver alloy phase floating as a dross on the liquid tin was removed regularly.

Material used in the study was a lead-free solder residue generated in Korea. Table 1 presents the average chemical compositions of the lead-free solder residue used in this work. The lead-free solder residue contains about $92.9 \% \mathrm{Sn}$ and $2.4 \% \mathrm{Ag}$. Samples before and after the silver separation experiments were analyzed for $\mathrm{Sn}, \mathrm{Cu}, \mathrm{Pb}$, and $\mathrm{Zn}$ by the inductively coupled plasma (ICP) method (JY-38 Plus, JobinYvon Equipment Co., London, UK) and Ag by the assaying

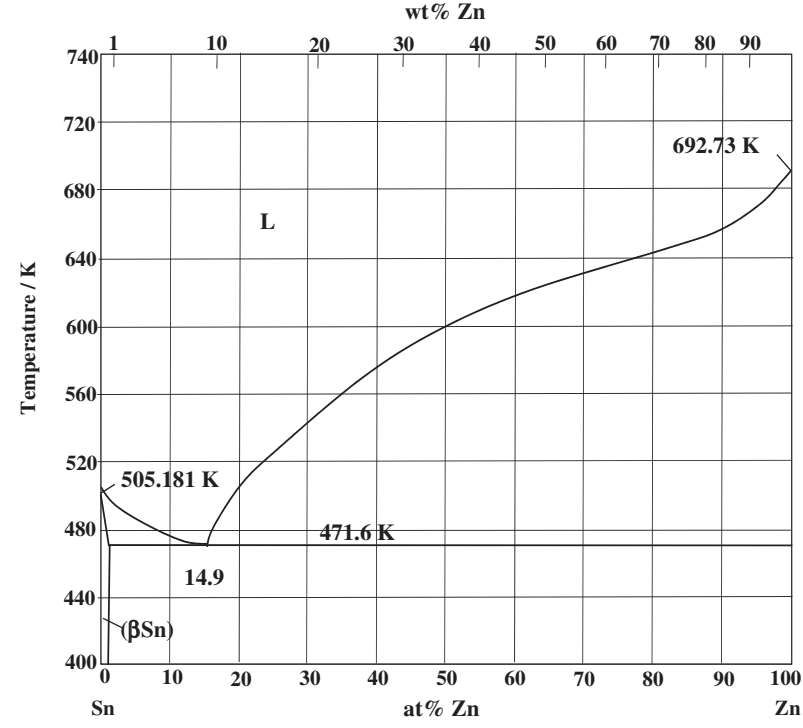

Fig. 3 Phase diagram of Sn-Zn system. ${ }^{4)}$

Table 1 Average chemical compositions of the lead-free solder residue used in this work (mass\%).

\begin{tabular}{ccccc}
\hline $\mathrm{Sn}$ & $\mathrm{Ag}$ & $\mathrm{Pb}$ & $\mathrm{Cu}$ & $\mathrm{Zn}$ \\
\hline 92.9 & 2.41 & 1.21 & 0.41 & 0.01 \\
\hline
\end{tabular}

method. In the present study, the percentage separation of silver was defined as:

$$
S_{\mathrm{Ag}}=\frac{O_{\mathrm{Ag}}-F_{\mathrm{Ag}}}{O_{\mathrm{Ag}}} X 100
$$




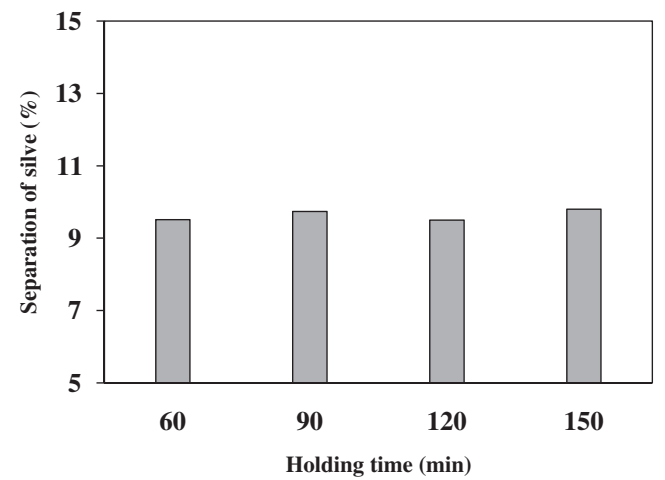

Fig. 4 The percentage separation of silver as a function of the holding time during the first silver separation stage under the conditions of the cooling temperature of $472 \mathrm{~K}$ and the addition amount of zinc of 21 mass $\%$.

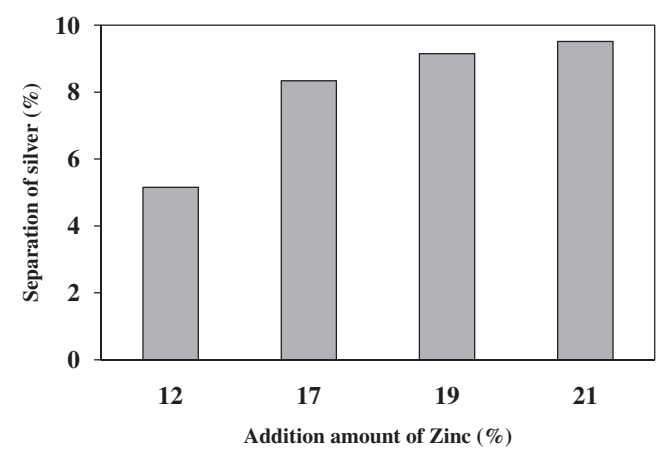

Fig. 5 The percentage separation of silver as a function of the amount of zinc added during the first silver separation stage under the conditions of the holding time of $60 \mathrm{~min}$ and the cooling temperature of $472 \mathrm{~K}$.

where, $\mathrm{S}_{\mathrm{Ag}}$ is the percentage separation of $\mathrm{Ag}, \mathrm{O}_{\mathrm{Ag}}$ is the weight $(\mathrm{g})$ of $\mathrm{Ag}$ in the lead-free solder residue before the experiment, and $\mathrm{F}_{\mathrm{Ag}}$ is the weight ( $\mathrm{g}$ ) of $\mathrm{Ag}$ remained in the liquid lead-free solder residue after the experiment.

\section{Results and Discussion}

Melting of lead-free solder residue started at around $673 \mathrm{~K}$ that is the higher temperature compared with the melting temperature of tin with a couple of percent silver because of the melting latent heat. Figure 4 shows the percentage separation of silver as a function of the holding time during the first silver separation stage under the conditions of the cooling temperature of $472 \mathrm{~K}$ and the addition amount of zinc of 21 mass $\%$. The figure indicates that the percentage separation of silver is almost steady to be $9.51 \%-9.80 \%$ at all the holding time considered in the study. Figure 5 shows the percentage separation of silver as a function of the amount of zinc added during the first silver separation stage under the conditions of the holding time of $60 \mathrm{~min}$ and the cooling temperature of $472 \mathrm{~K}$. The figure indicates that the percentage separation of silver increases with increasing in the addition amount of zinc. But, it is shown that the percentage separation is almost steady at the addition amount of zinc above 19 mass $\%$. The percentage separation of silver was relatively low to be $9.15 \%-9.51 \%$ at the addition amount of zinc above 19 mass $\%$. The low silver separation might be due to the small density difference between the liquid tin

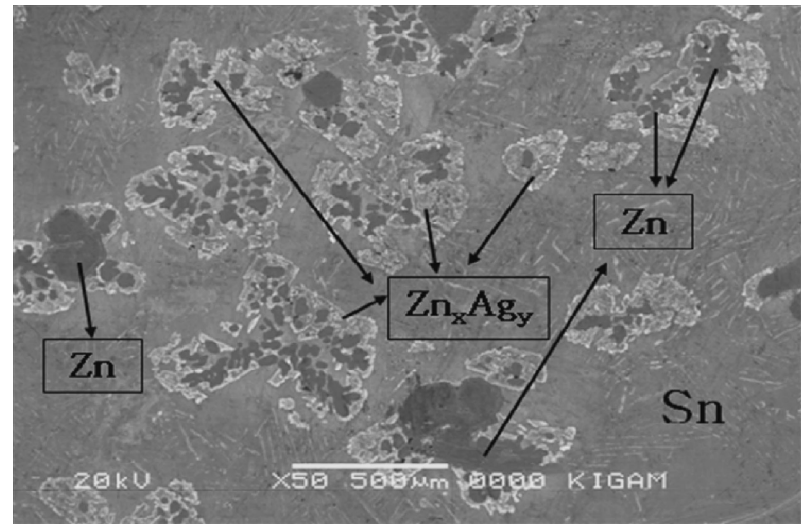

Fig. 6 SEM picture of the dross phase separated during the first silver separation stage.

Table 2 The percentage separation of silver obtained in cyclic silver separation stages including the addition amount of zinc.

\begin{tabular}{cccccc}
\hline & $\begin{array}{c}\text { First } \\
\text { stage }\end{array}$ & $\begin{array}{c}\text { Second } \\
\text { stage }\end{array}$ & $\begin{array}{c}\text { Third } \\
\text { stage }\end{array}$ & $\begin{array}{c}\text { Fourth } \\
\text { stage }\end{array}$ & Total \\
\hline $\begin{array}{c}\text { Addition amount } \\
\text { of Zn (mass\%) }\end{array}$ & 21.0 & 9.1 & 8.2 & 5.8 & \\
\hline $\begin{array}{c}\text { Percentage } \\
\text { separation } \\
\text { of Ag }(\%)\end{array}$ & 9.51 & 15.78 & 40.59 & 40.60 & 73.10 \\
\hline
\end{tabular}

metal phase and the zinc-silver alloy phase. Figure 6 shows SEM picture of the dross phase separated during the first silver separation stage. The figure indicates that the zinc phase is saturated with silver. Thus, it was verified that zinc metal could separate silver from the liquid lead-free solder residue because the zinc can form zinc-silver alloys floating as a dross phase on the liquid tin phase.

For the experiments of the cyclic silver separation stages, the experiment lasted about $10 \mathrm{~min}$ at $723 \mathrm{~K}$ with stirring (200 RPM) to alloy totally zinc with the tin-silver alloy obtained from the previous stage, after which the liquid phase was cooled down in air with stirring (200 RPM) until $472 \mathrm{~K}$, and then lasted about $60 \mathrm{~min}$ with skimming the zinc-silver alloy phase floating as a dross on the liquid tin phase every about $15 \mathrm{~min}$. The amount of zinc added at $723 \mathrm{~K}$ was calculated as explained in the experimental section for the first silver separation stage. After the first silver separation stage, the amount of zinc added in each stage was fixed to the tree times of the $\mathrm{Zn} / \mathrm{Ag}$ molar ratio of 2.5, which was calculated by the consideration of the formation of a zincsilver alloy of $\mathrm{Ag}_{2} \mathrm{Zn}_{5}$, for the silver content remained in the tin-silver alloy obtained from the previous stage. The results for the percentages separation of silver obtained in the cyclic silver separation stages including the addition amount of zinc are summarized in Table 2, which shows that the percentage separation of silver is almost steady above the third stage. Based on the experimental results, the total percentage separation of silver was calculated to become over $90 \%$ through the sixth silver separation stage at the above conditions. Therefore, it was considered that the process developed is a possible method to separate and recover silver from lead-free solder residues. 


\section{Conclusion}

A novel cyclic process to separate silver from lead-free solder residue using zinc as a metal solvent was developed in the study. The proposed process consisted of two major steps, silver separation and zinc volatilization separation steps. The percentage separation of silver was $9.15 \%-9.51 \%$ at the addition amount of zinc above 19 mass $\%$ in the first silver separation stage and the total percentage separation through the forth silver separation stage was about $73.10 \%$. Using the process developed, up to $90 \%$ of the silver in the lead-free solder residue was calculated to be separated into the dross phase through the sixth silver separation stage.

\section{Acknowledgement}

This research was supported by the Basic Research Project of the Korea Institute of Geosciences and Mineral Resources (KIGAM) funded by the Ministry of Knowledge and Economy of Korea.

\section{REFERENCES}

1) RECOM Co. LTD, Hwaseong-city, Gyeonggi-do, Korea, private communication (February 2009).

2) P. A. Wright: Extractive metallurgy of tin, (New York, Elsevier science publishing company Inc., 1982) pp. 241-252.

3) M. Hansen and K. Anderko: Constitution of Binary Alloys, (New York, McGraw-Hill Book Co., 1958) p. 52.

4) http://www.springerlink.com/content/v5j647p44615mx06/ fulltext.pdf?page $=1$

5) C. B. Gill: Nonferrous Extractive Metallurgy, (New York, JOHN WILEY \& SONS Inc., 1980) p. 112.

6) M. Srivastava and R. Sharma: J. Phase Equilib. 14 (1993) 700-709.

7) D. Masson and J. Sheu: Metall. Trans. 1 (1970) 3005-3009. 